\title{
Fixed combinations in the management of hypertension: patient perspectives and rationale for development and utility of the olmesartan - amlodipine combination
}

\author{
Eduardo Pimenta' \\ Suzanne Oparil ${ }^{2}$ \\ 'Department of Hypertension \\ and Nephrology, Dante Pazzanese \\ Institute of Cardiology, Sao Paulo, \\ SP, Brazil; ${ }^{2}$ Vascular Biology and \\ Hypertension Program, University of \\ Alabama at Birmingham, Birmingham, \\ AL, US
}

Correspondence: Eduardo Pimenta Av. Dr. Dante Pazzanese, 500, Sao Paulo, SP, Brazil, 04012-909

Tel +55 I I 50856 | 44

Email espimenta@hotmail.com

\begin{abstract}
Although the awareness and control of hypertension has increased, only $37 \%$ of hypertensive patients in the US achieve the conservative goal of $<140 / 90 \mathrm{mmHg}$. Achieving optimal blood pressure (BP) control is the most important single issue in the management of hypertension, and in most hypertensive patients, it is difficult or impossible to control BP with one drug. Blocking two or more BP regulatory systems provides a more effective and more physiologic reduction in $\mathrm{BP}$, and current guidelines have recommended the use of combination therapy as first-line treatment, or early in the management of hypertension. Fixed combination therapy is an efficacious, relatively safe, and may be cost-effective method of decreasing BP in most patients with essential hypertension. Similar to other combinations, fixed-dose combination tablets containing the dihydropyridine calcium channel blocker amlodipine and the angiotensin II receptor blocker olmesartan bring together two distinct and complementary mechanisms of action, resulting in improved BP control and potential for improved target organ protection relative to either class of agent alone.
\end{abstract}

Keywords: olmesartan - amlodipine, hyptertension, combination therapy

\section{Introduction}

Hypertension is a highly prevalent condition and an important modifiable risk factor for cardiovascular (CV) disease. Hypertension affects nearly 1 in 3 adults in the US, with a prevalence of $29.3 \%$ in a population $\geq 18$ years old (Hajjar and Kotchen 2003; Ong et al 2007; Rosamond et al 2008), and as many 1.5 billion persons worldwide will have hypertension by 2025 (Kearney et al 2005).

Hypertension is the most common risk factor for CV death and disability in both developed and developing countries, and control of blood pressure (BP) significantly reduces these risks (Turnbull et al 2003; Kearney et al 2005). Observational studies have shown that mortality from ischemic heart disease and stroke in persons 40-89 years of age increases in log linear fashion with increases in both systolic (SBP) and diastolic BP (DBP) (Lewington et al 2002). For each increase in SBP of $20 \mathrm{mmHg}$ or in DBP of $10 \mathrm{mmHg}$ over the entire range from $115 / 75 \mathrm{mmHg}$, there is a twofold increase in mortality related to coronary artery disease and stroke.

Although the awareness and control of hypertension have increased, only $37 \%$ of hypertensive patients in the United States achieve the conservative goal of $<140 / 90 \mathrm{mmHg}$ (Ong et al 2007). Achieving optimal BP control is the most important single issue in the management of hypertension, and in most hypertensive patients, it is difficult or impossible to control BP with one drug. For example, in the very large Antihypertensive and Lipid Lowering Treatment to Prevent Heart Attack (ALLHAT) trial less than 
$30 \%$ of more than 42,000 participants achieved goal BP $(<140 / 90 \mathrm{mmHg}$ ) on monotherapy (Cushman et al 2002). In the Losartan Intervention For Endpoint (LIFE) trial, in which treatment to goal $(<140 / 90 \mathrm{mmHg})$ was aggressively pursued in $>9,000$ patients with left ventricular hypertrophy (LVH) and an average baseline BP of 175/98 $\mathrm{mmHg},>90 \%$ required more than one antihypertensive agent (Dahlöf et al 2002). Although participants in the LIFE trial had free medications and close follow-up, only $49 \%$ of patients assigned to losartan and $46 \%$ assigned to atenolol achieved the BP goal ( $<140 / 90 \mathrm{mmHg})$.

Based on clinical trials, current guidelines have recommended the use of combination therapy as first-line treatment, or early in the management of hypertension in patients with comorbidities that require prompt BP reduction. Initial treatment with 2 antihypertensive agents is suggested for persons with BP $>20 / 10$ mmHg above goal (Figure 1) (Chobanian et al 2003; Mancia et al 2007).

\section{Patient adherence}

Patient adherence refers to the willingness and ability of an individual patient to follow health-related advice, take medication as prescribed, attend scheduled clinic appointments, and complete recommended tests and consultations (Murphy and Coster 1997). Poor adherence to medication regimens contributes to the practice - outcome gap, in which clinical guidelines are implemented but expected benefits are not realized. For example, in one study, nonadherence to medication was by far the leading cause of hospitalization in a series of 179 patients admitted to hospital with acute decompensation of pre-existing heart failure, being implicated in $42 \%$ of hospital admissions (Michalsen et al 1998). In another study of 1,015 outpatients with stable coronary heart disease, self-reported medication nonadherence was associated with a greater than 2-fold increased rate of subsequent $\mathrm{CV}$ events, such as coronary heart disease death, myocardial infarction, and stroke (Gehi et al 2007).

Multiple medications and complexity of treatment regimen are two of the determinants of poor medication adherence. A survey conducted by the National Council on Patient Information and Education showed that one-third of patients receive at least 2 prescriptions and $10 \%$ of patients receive 4 or more prescriptions after a visit to a primary care physician (Dezii 2000). This survey also has estimated that the adherence rate is in the range of $30 \%$ for chronic conditions.

There is a clear inverse relationship between complexity of the dosing regimen/number of drugs that patients have to take and patient adherence. Adherence to antihypertensive agents varies inversely with dosing frequency (Sica 1994). For example, among 198 Canadian hypertensives randomized to diltiazem twice-daily compared with amlodipine oncedaily, those on the once-daily regimen took the medication more regularly than those on twice-daily dosing (Leenen et al 1997). Among 91 diabetic patients using oral antidiabetic agents, the adherence rate, defined as the percentage of doses taken during the observation period, fell from $79 \%$ on oncedaily to 38\% on 3-times daily dosing (Paes et al 1997).

Adherence to antihypertensive treatment is inversely related to achieved BP levels, ie, nonadherent patients tend to have higher BP than adherents. In a prospective study of 347 hypertensive patients, BP levels were compared between adherents and nonadherents with antihypertensive treatment (Khalil and Elzubier 1997). Patients were considered adherent if the number of pills prescribed or dispensed - the number of pills missed/number of pills prescribed or dispensed for the interval time $\times 100$ was $>80 \%$. BP was significantly lower in adherent than in nonadherent patients.

Adherence rate is also inversely related to the number of drugs given. Patients are more adherent when they take a combination as a single tablet than if they are given the same drugs as 2 separate pills, even when dosed once daily (Neutel 2005). A meta-analysis of 9 studies which compared fixed-dose combinations versus free-drug components of the regimen separately for treatment of hypertension (4 studies), diabetes (2 studies), tuberculosis (2 studies), and human immunodeficiency virus (HIV) disease (1 study), showed that fixed-dose combinations decreased rate of nonadherence by $26 \%$ compared with free-drug component regimens (Bangalore et al 2007). A subgroup analysis of the four studies in hypertension showed that fixed-dose combinations decreased the risk of medication nonadherence by $24 \%$ compared with free-drug combinations (Figure 2) (Bangalore et al 2007).

Fixed-dose combination therapy is an efficacious, relatively safe, and possibly cost-effective method of decreasing BP in most patients with essential hypertension (Sica 2002). Initiating therapy with more than one agent offers the potential advantages of achieving BP control more rapidly and avoiding dose-related adverse effects of individual drugs by producing greater BP reductions at lower doses of the component agents. Fixed-dose combinations also have other advantages (Table 1) (Lewanczuk and Tobe 2007; Woodham and Oparil 2007).

Adherence to antihypertensive treatment increases with fixed-dose combinations (Figure 3). Adherence to a fixeddose combination of the calcium channel blocker (CCB) amlodipine with the angiotensin converting-enzyme (ACE) 


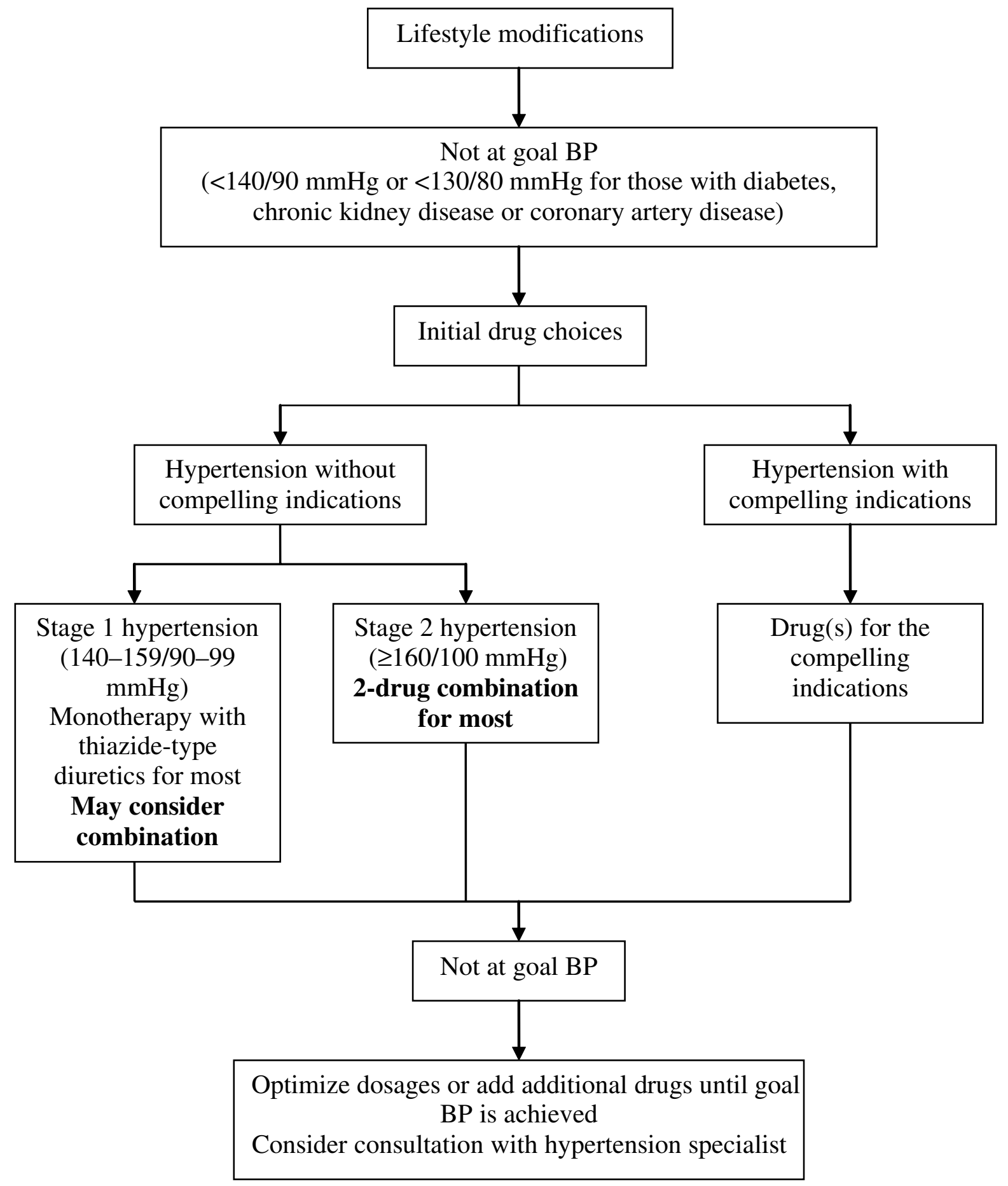

Figure I Algorithm for treatment of hypertension. BP, blood pressure. Modified from Chobanian et al (2003).

inhibitor benazepril has been compared with adherence to free-dose combination therapy of the two agents in a retrospective analysis of data obtained from a pharmacy claims database in the US (Wanovich and Kerrish 2004). Patients who received 2 or more prescriptions for the fixed-dose combination $(\mathrm{n}=2,839)$ or the two components separately $(\mathrm{n}=3,367)$ were identified and followed up for an average of 259 days and 247 days, respectively. Adherence to fixed-dose combination therapy was significantly greater than for free combination therapy, $88 \%$ vs $69 \%$, respectively. In another study, hypertensive subjects receiving once-daily, singlecapsule, fixed-dose combination of amlodipine - benazepril 


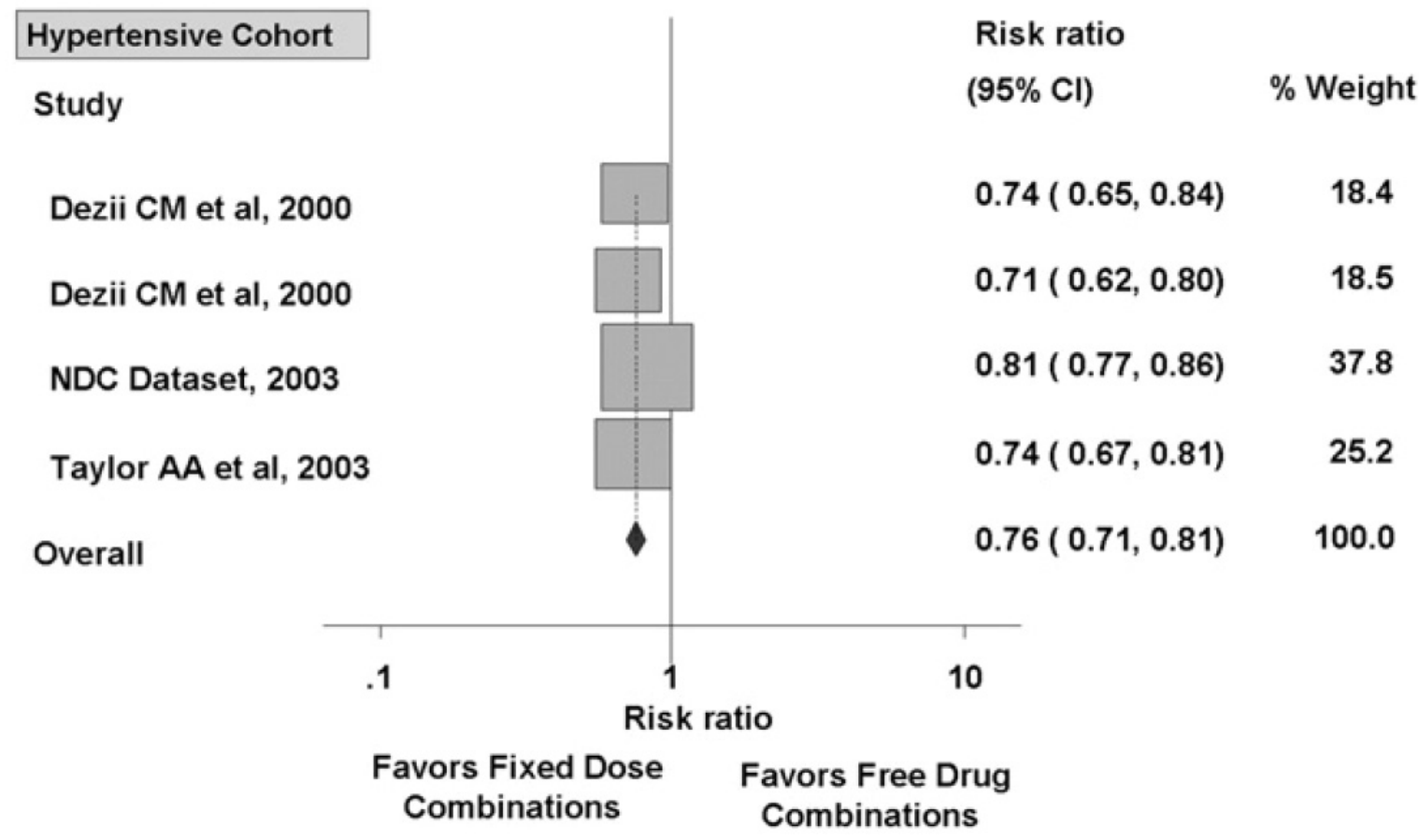

Heterogeneity $\mathrm{chi}^{2}=6.30(p=0.10)$

Publication Bias (Egger's) $\mathrm{p}=0.05$

Figure 2 Effect of fixed-dose combinations versus free-drug combination on the risk of medication nonadherence in cohort with hypertension. Reprinted from Bangalore S, Kamalakkannan G, Parkar S, et al 2007. Fixed-dose combinations improve medication compliance: a meta-analysis. Am J Med 120:713-19. Copyright @ 2007, with permission from Elsevier.

demonstrated significantly better medication adherence than subjects receiving an $\mathrm{ACE}$ and a $\mathrm{CCB}$ as separate components, $80.8 \%$ vs $73.8 \%$, respectively (Taylor and Shoheiber 2003). The average annual cost of CV-related care per subject was also significantly lower in hypertensive patients receiving the fixed-dose.

The most important reason for use of combination therapy in clinical practice is that combining two antihypertensive agents with complementary mechanisms of action produces significantly greater BP reducing efficacy than either of the components as monotherapy (Chrysant 1994; Chrysant et al

Table I Advantages of fixed-dose combination therapy

- Increased compliance, simplified titration, and convenience of use.

- Potentiation of antihypertensive effects of single compounds.

- Additive or synergistic effects.

- Enhancing effect in specific populations.

- Attenuation in adverse events.

- Decreases in diuretic-induced metabolic changes with ACE inhibitors or ARBs.

- Decrease in calcium channel anatagonist-related peripheral edema with ACE inhibitors or ARB.

- Improved overall results, greater BP response, and lower cost.

Abbreviations: $A C E$, angiotensin-converting enzyme; $A R B$, angiotensin II receptor blocker; BP, blood pressure.
2004; Hasebe 2005). As hypertension is multifactorial and many pathophysiologic factors contribute to high BP, the combination of agents with different (and complementary) mechanisms of action provides more complete blockade of pressor mechanisms with less activation of counter-regulatory mechanisms. For example, diuretics activate the reninangiotensin-aldosterone system (RAAS), reduce volume, and make BP more angiotensin dependent. Concomitant administration of an ACE inhibitor or an angiotensin II receptor blocker (ARB) blocks angiotensin II generation or action, minimizing the compensatory pressor effect of diuretic-induced RAAS activation and producing an additive BP-lowering effect.

Combination therapy also improves tolerability by reducing dose-dependent side effects (clinical or metabolic) of individual components. Upward dose titration in an attempt to avoid the addition of a second agent often leads to increases in dose-dependent side effects, resulting in discontinuation of therapy. Appropriate combination therapy can also improve tolerability if one component can neutralize the adverse effects of the second agent. For example, the tendency for thiazides to cause hypokalemia is blunted by concomitant use of potassium-sparing diuretics, ACE inhibitors, or ARBs. In 


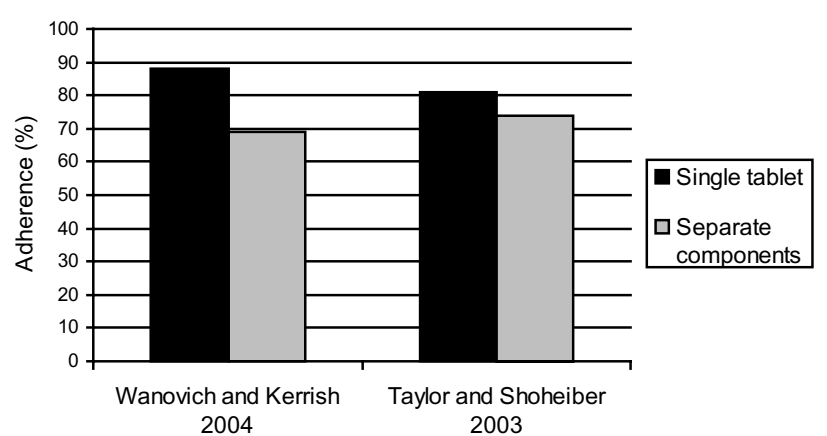

Figure 3 Medication adherence with combination of amlodipine/benazepril singletablet compared to same combination as separate components.

a prospective 8-week study of 1,346 hypertensive patients, the incidence of hypokalemia was lower in those assigned to receive valsartan - hydrochlorothiazide (HCTZ) than in those assigned to HCTZ monotherapy (Pool et al 2007). Further, the peripheral edema caused by the dihydropyridine CCB amlodipine is reduced with ARBs or ACE inhibitors (Messerli et al 2000; Neutel et al 2005; Philipp et al 2007). For example, in a prospective randomized double-blind study of 1,079 hypertensive patients who were assigned to receive amlodipine/benazepril or amlodipine or nifedipine monotherapy, the incidence of edema was $15 \%$ in the highdose nifedipine group and $24 \%$ in the high-dose amlodipine group and was greatly reduced in patients treated with any dose of combination therapy $(1.5 \%-3.8 \%)$ or low-dose CCB (4.9\%-5.4\%) (Messerli et al 2000). In another prospective study of 1,911 patients, the incidence of peripheral edema was significantly lower in patients randomized to receive the ARB valsartan plus amlodipine than in patients treated with amlodipine monotherapy (5.4\% vs $8.7 \%$, respectively; $\mathrm{p}=0.014)$ (Philipp et al 2007).

\section{Overview of currently available fixed combinations}

The very earliest outcome trial of antihypertensive therapy, the Veteran's Administration Cooperative Study on Antihypertensive Agents, demonstrated dramatic reductions in $\mathrm{CV}$ outcomes with a triple combination of HCTZ, reserpine, and hydralazine compared with placebo (Veterans Administration Cooperative Study 1967). Fixed-dose combinations of newer antihypertensive drugs have been developed in recent years, in response to the realization that most patients require multiple antihypertensive agents for BP control (Prisant et al 1995). The currently available fixed-combination therapies are listed in Table 2.

$\mathrm{ACE}$ inhibitor - diuretic or ARB - diuretic combinations are the most commonly used fixed-dose combination antihypertensive agents because of an additive effect on BP reduction related to complementary mechanisms of action of the components and the favorable vascular, metabolic, cardiac, and renoprotective effects of the ACE inhibitors and ARBs (Lewis et al 1993; Weir and Dzau 2001; Chobanian et al 2003). Randomized controlled clinical trials that compared the combination versus monotherapy with either ACE inhibitor or HCTZ have generally demonstrated greater BP-lowering efficacy with low-dose combinations over higher-dose monotherapy with either single agent. In a representative trial, patients were randomized to 8 weeks of placebo, lisinopril $10 \mathrm{mg}$, HCTZ $12.5 \mathrm{mg}$, HCTZ $25 \mathrm{mg}$, or combination therapy with lisinopril $10 \mathrm{mg}$ and either HCTZ

Table 2 Currently available combination antihypertensives in US in 2007

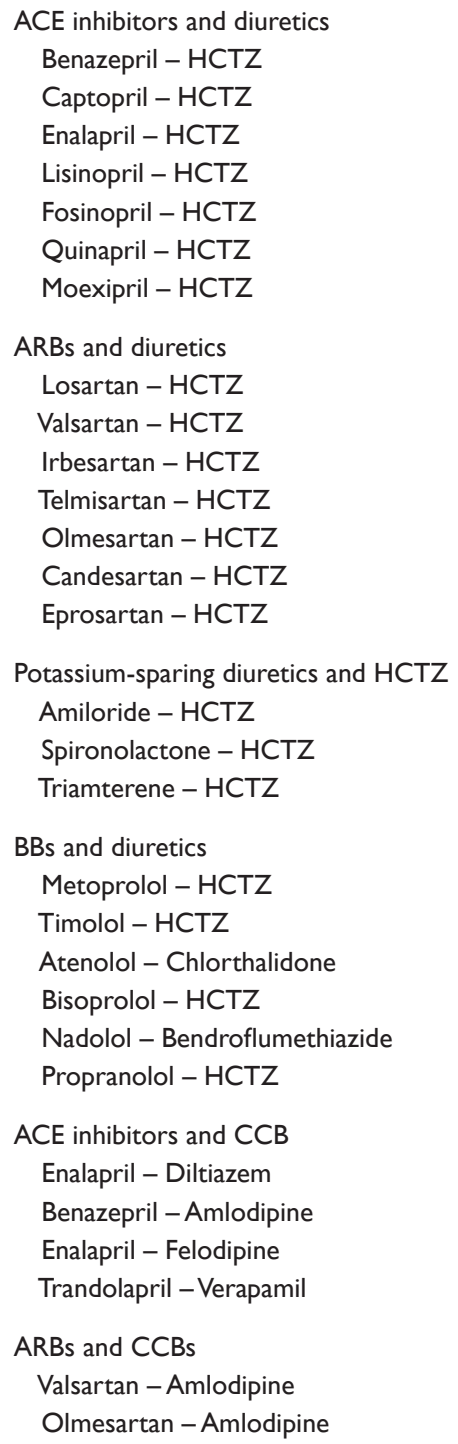

Abbreviations: $A C E$, angiotensin-converting enzyme; $A R B$, angiotensin II receptor blocker; $\mathrm{BB}, \beta$-blockers; $\mathrm{CCB}$, calcium-channel blockers; $\mathrm{HCTZ}$, hydrochlorothiazide. 
$12.5 \mathrm{mg}$ or $25 \mathrm{mg}$ (Chrysant 1994). Monotherapy with either agent lowered DBP by $6-8 \mathrm{mmHg}$ over placebo, and combination therapy produced a further $6-7 \mathrm{mmHg}$ reduction in DBP. BP response rate, defined as a decrease in DBP of $>10 \mathrm{mmHg}$ or achieving a goal of $<90 \mathrm{mmHg}$, was higher with combination therapy $(70 \%-80 \%)$ than with lisinopril or HCTZ monotherapy (40\%-50\%).

Similarly, studies of ARB - diuretic combinations have demonstrated significantly greater reductions in SBP and DBP compared with monotherapy with either individual agent. A representative factorial study evaluated the efficacy of regimens that included either olmesartan 10-40 mg a day, HCTZ 12.5 or $25 \mathrm{mg}$ a day, placebo, or the combination of olmesartam and HCTZ (Chrysant et al 2004). The greatest effect on BP was noted in the arm receiving $40 \mathrm{mg}$ of olmesartan and $25 \mathrm{mg}$ of HCTZ, in which SBP decreased by $23.5 \mathrm{mmHg}$ and DBP by $13.7 \mathrm{mmHg}$ more than with placebo (Figure 4). The addition of diuretic to placebo or to any dose of olmesartan produced an additional BP response compared with placebo or olmesartan alone. Control $(<140 / 90 \mathrm{mmHg})$ rates were greater in patients taking the highest dose of the combined agents than in those taking the highest doses of monotherapies.

ACE inhibitor - CCB combinations also have additive antihypertensive effects and offer the added advantage of minimizing adverse effects of individual components (eg, edema with dihydropyridine CCBs). The Anglo-Scandinavian Cardiac Outcomes Trial-Blood Pressure Lowering Arm (ASCOTBPLA) presented evidence that a $\mathrm{CCB}$ - ACE inhibitor combination is more effective in lowering $\mathrm{BP}$ and reducing risk of mortality and major CV events than traditional therapy with a $\beta$-blocker (BB) - thiazide combination (Dahlöf et al 2005; Poulter et al 2005). ASCOT included 19,257 hypertensive patients randomly assigned to either amlodipine-based treatment (with the option of adding perindopril) or to atenolol-based treatment (with the option of adding bendroflumethiazide). $\mathrm{BP}$ control was defined as $<140 / 90 \mathrm{mmHg}$ in patients without diabetes and $<130 / 80 \mathrm{mmHg}$ with diabetes. The CCB $-\mathrm{ACE}$ inhibitor combination lowered BP by an average of 2.7/1.9 $\mathrm{mmHg}$ more than the $\mathrm{BB}$ - diuretic combination throughout the 5.5 year median follow-up period. Significant reductions in a number of outcomes (all-cause mortality, nonfatal myocardial infarction, and new-onset diabetes) were noted with $\mathrm{CCB}-\mathrm{ACE}$ inhibitor compared with BB - diuretic. Importantly, by the end of the trial only $15 \%$ and $9 \%$ of participants were taking amlodipine or atenolol monotherapy, respectively, providing additional evidence for the inadequacy of monotherapy for BP control.
Similar to the ACE inhibitor - CCB combination, $\mathrm{ARB}-\mathrm{CCB}$ combinations have showed efficacy in reducing BP. The Nifedipine and Candesartan Combination Study (NICE Combi) randomized 258 hypertensive patients to receive controlled-release nifedipine $20 \mathrm{mg}$ plus candesartan $8 \mathrm{mg}$ in combination or up-titration of candesartan $12 \mathrm{mg}$ monotherapy (Hasebe et al 2005). BP reduction was significantly greater in the combination therapy group $(12.1 / 8.7)$ than in the up-titrated monotherapy group (4.1/4.6, $\mathrm{p}<0.0001)$ after 8 weeks of follow-up. The NICE Combi study provides additional evidence that low-dose fixed combination therapy is more effective in reducing BP than monotherapy in high-dose.

ACE inhibitor - CCB combination therapy has become widely used due to high efficacy in reducing BP and high tolerability. Evidence that both CCBs and ACE inhibitors have beneficial effects on endothelial function (Taddei et al 2000) has also led to the hypothesis that, for the same BP effects, an ACE inhibitor - CCB combination may have outcome advantages over an ACE inhibitor - diuretic combination. Further, it has been hypothesized that the neutral metabolic effects of amlodipine, in contrast to the adverse metabolic effects of diuretics, translate into better clinical outcomes, even when each agent is combined with an ACE inhibitor. The latter argument has provided the rationale for the Avoiding Cardiovascular events through COMbination therapy in Patients Living with Systolic Hypertension (ACCOMPLISH) trial, the first randomized controlled blinded study to compare prospectively the effects of 2 fixed combinations of antihypertensive drugs, benazepril - amlodipine and benazepril - HCTZ on CV disease outcomes in high-risk hypertensive patients (Jamerson et al 2004). The primary study endpoint is a composite of $\mathrm{CV}$ mortality and morbidity and the secondary endpoints include new onset diabetes, progression of renal disease, and hospitalization for congestive heart failure. Early unblinded results from 10,704 participants from both treatment groups combined have shown higher BP control rates compared with previous clinical trials (Jamerson et al 2007). The 6-month BP control rate $(<140 / 90 \mathrm{mmHg})$ was $73 \%$ in the overall trial (78\% in the US); $43 \%$ of diabetics and $40 \%$ of patients with renal disease achieved the more aggressive BP goal of $<130 / 80 \mathrm{mmHg}$. Serious hypotensive events occurred in only $1.8 \%$, suggesting that these combinations are appropriate and safe for hypertensive patients who are at high-risk. Final results of ACCOMPLISH will provide insight into whether CCB - RAAS inhibitor combination therapy offers advantages over diuretic-RAAS inhibitor combinations in 

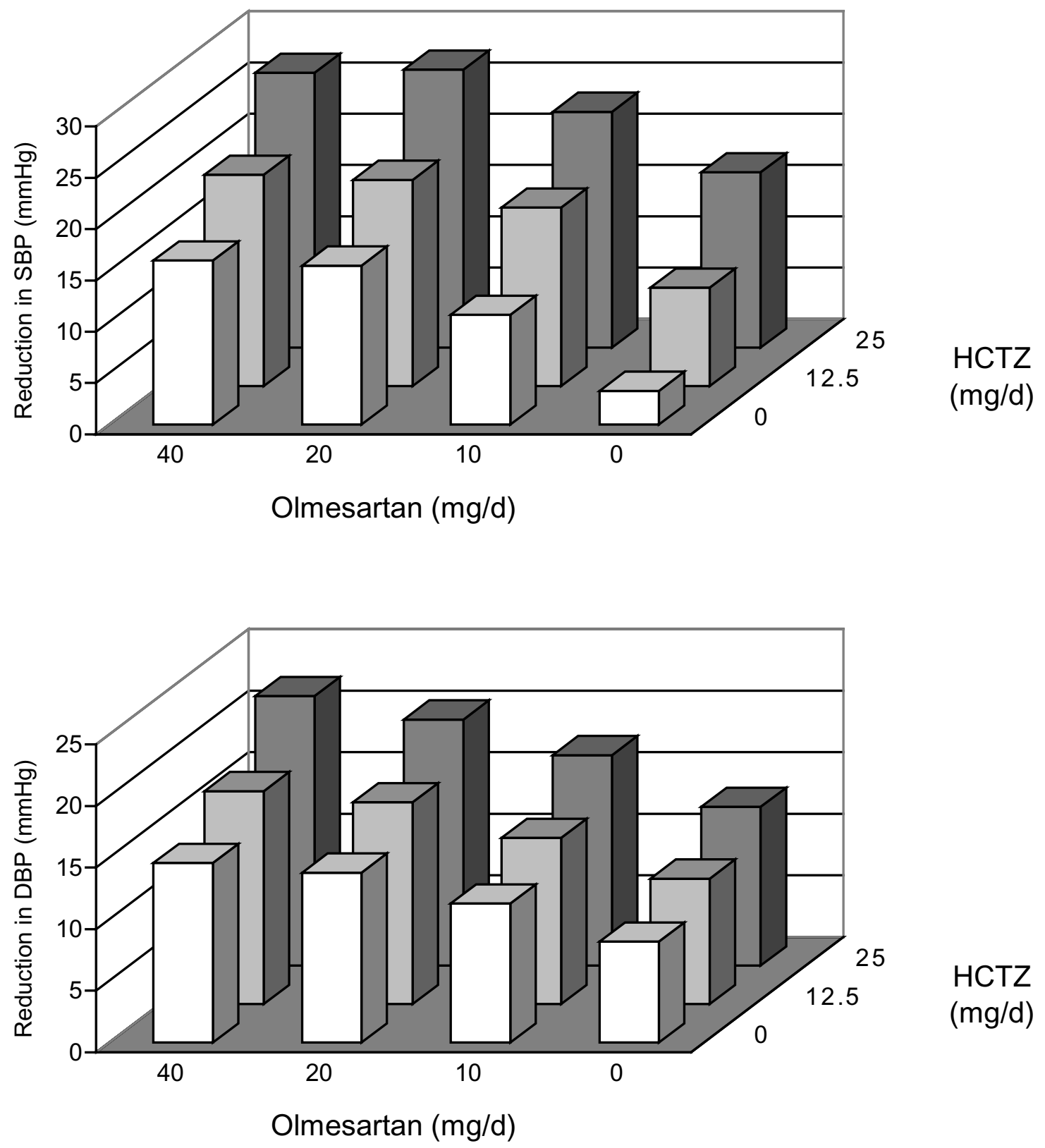

Figure 4 Reduction (model fitted) in seated systolic blood pressure (SBP) (upper panel) and seated diastolic blood pressure (DBP) (lower panel) for 12 groups in the factorial design by olmesartan medoxomil and hydrochlorothiazide (HCTZ) dosage. Adapted by permission from Macmillan Publishers Ltd: Chrysant SG, Weber MA, Wang AC, et al 2004. Evaluation of antihypertensive therapy with combination of olmesartan medoxomil and hydrochlorothiazide. Am J Hypertens 17:252-9. Copyright @ 2004.

lowering BP, minimizing adverse effects, and preventing morbid and mortal CV events.

\section{Amlodipine}

Pharmacology

Dihydropyridine $\mathrm{CCBs}$ act by decreasing $\mathrm{Ca}^{2+}$ entry to cells through the L-type $\mathrm{Ca}^{2+}$ channel (Krum 1997; Messerli 2003). Decreased availability of intracellular $\mathrm{Ca}^{2+}$ in arterial smooth muscle cells prevents actin and myosin from interacting, resulting in vasodilation (Prisant 2005). Dihydropiridine
CCBs also facilitate natriuresis by increasing renal blood flow, dilating afferent arterioles, and increasing glomerular filtration pressure.

Amlodipine is a long-acting third generation dihydropyridine $\mathrm{CCB}$ that is the most commonly used agent in its class for the treatment of hypertension (Abernethy and Schwartz 1999; Basile 2004). More than $90 \%$ of amlodipine is absorbed and $95 \%$ of circulating amlodipine is bound to plasma proteins. It does not have an extensive hepatic firstpass metabolism, which contributes to its prolonged effect. 
The time to peak effect of amlodipine is 10-14 hours; its elimination half-life is $35-45$ hours and steady-state plasma levels are reached after 7-8 days of consecutive daily dosing (Prisant 2005). About $90 \%$ of amlodipine is converted to inactive metabolites via hepatic metabolism, and $60 \%$ of the metabolites are excreted in the urine. In patients with chronic kidney disease, the pharmacokinetics of amlodipine are minimally changed. In hepatic disease, diminished systemic clearance may necessitate dosage adjustments. Aging slows the metabolism of amlodipine, presumably secondary to the accompanying decrease in hepatic blood flow, sometimes necessitating dosage adjustments in the elderly (Prisant 2005; Weir 2008). Amlodipine may cause reflex tachycardia early in the course of therapy or at very high doses, but this sympathoexcitatory effect is not evident with usual clinical doses or with long term treatment (Weir 2008).

\section{Efficacy and safety}

Amlodipine effectively lowers BP and is also effective in reducing $\mathrm{CV}$ disease outcomes, both morbid and mortal, with the exception of heart failure. In the Antihypertensive and Lipid-Lowering Treatment to Prevent Heart Attack Trial (ALLHAT), more than 40,000 high risk hypertensive patients were randomly assigned to receive chlorthalidone, amlodipine, lisinopril, or doxazosin (ALLHAT 2002). Participants were men and women aged 55 years or older who had stage 1 or stage 2 hypertension with at least 1 additional risk factor for coronary heart disease events. ALLHAT tested the hypothesis that the newer drug classes (CCBs, ACE inhibitors, $\alpha$-blockers) are superior to the thiazide-like diuretics in preventing fatal and nonfatal coronary events. Thus, due to the design of the trial, the effects of a RAAS inhibitor-CCB combination could not be tested. ALLHAT is the only large outcome trial in hypertension that has included a racially/ ethnically diverse patient population (35\% Black, 19\% Hispanic) and a large (36\%) population of diabetics. Amlodipine was as effective as chlorthalidone in reducing the primary combined endpoint of fatal coronary heart disease or nonfatal myocardial infarction. In addition, amlodipine was effective in reducing combined coronary heart disease events and endstage renal disease. However, incidence of heart failure was $38 \%$ higher in patients assigned to amlodipine than patients assigned to chlorthalidone in the absence of concomitant RAAS inhibitor therapy in either group. There was no significant difference in adverse effects between amlodipine and chlorthalidone based therapy, refuting previous claims that dihydropyridine CCBs precipitate coronary events.
The Valsartan Antihypertensive Long-Term Use Evaluation (VALUE) trial compared the effects of amlodipine and valsartan as first-line therapy in reducing $\mathrm{CV}$ outcomes in hypertensive patients at high CV risk (Julius et al 2004). Amlodipine treatment was associated with a more prompt and robust reduction in BP than valsartan treatment, particularly early in the trial when participants were on monotherapy. In the study as a whole, amlodipine treatment was associated with a significantly greater reduction in the incidence of nonfatal myocardial infarction compared with valsartan treatment. Subanalysis of VALUE results reported that patients treated with amlodipine monotherapy had a $22 \%$ higher risk of heart failure than those treated with valsartan monotherapy; there were no other significant outcome differences (Julius et al 2006). These data are consistent with the findings in ALLHAT that amlodipine does not prevent heart failure as effectively as some other antihypertensive drugs. However, data from Prospective Randomized Amlodipine Survival Evaluation (PRAISE) study showed that amlodipine does not increase CV morbidity or mortality in patients with severe heart failure, suggesting that this CCB does not worsen established heart failure (Packer et al 1996).

In ASCOT, the amlodipine - perindopril regimen was more effective in reducing $\mathrm{BP}$ and preventing $\mathrm{CV}$ events than the atenolol - bendroflumethiazide regimen (Dahlöf et al 2005). BP was, on average, 2.7/1.9 mmHg lower in the amlodipine group than in the atenolol group during 5.7 years of follow-up. Amlodipine \pm perindopril was also superior in preventing fatal and nonfatal stroke, total $\mathrm{CV}$ events and procedures, and all-cause mortality than atenolol \pm bendroflumethiazide. Interestingly, the incidence of fatal and nonfatal heart failure did not differ between amlodipine- and atenolol-based regimens, suggesting that blocking the RAAS neutralizes the adverse effects of amlodipine monotherapy. By the end of the trial, $85 \%$ of patients assigned to amlodipine and $91 \%$ of those assigned to atenolol were taking at least 2 antihypertensive agents, reinforcing the concept that combination therapy is needed to control BP in high risk hypertensive patients. There was a significant difference in favor of the amlodipine-based regimen in the proportion of patients who stopped the trial therapy because of serious adverse events.

Amlodipine has been proven effective in decreasing left ventricular mass in hypertensive patients. In a 1-year prospective study of 59 patients with diastolic hypertension who were randomized to lisinopril or amlodipine, amlodipine decreased left ventricular mass as effectively as lisinopril $\left(-11.0 \mathrm{~g} / \mathrm{m}^{2} \mathrm{vs}-12.6 \mathrm{~g} / \mathrm{m}^{2}\right.$, respectively) (Beltman et al 1988). 
Further, in the Effects of Amlodipine and Lisinopril on Left Ventricular Mass and Diastolic Function (ELVERA) trial, which compared amlodipine with lisinopril therapy in 166 elderly patients with hypertension (95-115/160-220 mmHg), amlodipine and lisinopril reduced left ventricular mass and improved diastolic function to a similar extent after 2 years of follow-up (Terpstra et al 2001).

\section{Olmesartan}

\section{Pharmacology}

ARBs lower BP by selectively blocking the binding of angiotensin II to the AT1 receptor in vascular smooth muscle and other cell types (Ruddy and Kostis 2005). Olmesartan medoxomil, the most recently developed ARB, is rapidly and completely bioactivated by ester hydrolysis in the gut wall to the pharmacologically active compound olmesartan, with peak plasma concentrations achieved between 1 and 3 hours and an elimination half-life of 12-18 hours (Laeis et al 2001; Schwocho and Masonson 2001). The absolute bioavailability of olmesartan medoxomil after oral administration is $26 \%-28.6 \%$. Steady-state plasma concentrations are reached within the first few days, and accumulation is not noted on long-term dosing. Olmesartan is not metabolized; $35 \%-50 \%$ of the systemically available active compound is excreted unchanged in the urine and the remainder in the bile. Olmesartan medoxomil has minimal or no inhibitory activity on human cytochrome p450 (Laeis et al 2001; Schwocho and Masonson 2001). Olmesartan has a unique mechanism of binding to the AT1 receptor that appears to contribute to its sustained duration of AT1 receptor blockade (Miura et al 2006, 2008). This involves the "double chain domain", whereby olmesartan binds to the receptor at 2 sites, a-OH group and an $\alpha-\mathrm{COOH}$ group, whereas other ARBs bind only at the $-\mathrm{OH}$ group. It has been shown that olmesartan produces more sustained inhibition of the pressor effects of infused angiotensin than other ARBs in normotensive adults, suggesting a more prolonged blockade of the AT1 receptor. It has been hypothesized (but not proven) that this sustained pressor inhibition is a function of the "double chain domain" binding.

\section{Efficacy and safety}

Olmesartan reduces BP rapidly and effectively in hypertensive patients. An analysis of 7 randomized, double-blind, placebo-controlled, parallel-group studies compared the safety and efficacy of olmesartan monotherapy with placebo in patients with essential hypertension (Neutel 2001). Olmesartan produced dose-dependent BP reductions in both
DBP and SBP within 1 week of initiating treatment, and the response was nearly maximal within 2 weeks.

At traditionally recommended starting doses, olmesartan reduces BP more effectively than other ARBs (Oparil et al 2005). A 588 patient, multicenter, randomized, double-blind, trial that compared once-a-day therapy with the recommended starting doses of losartan, valsartan, and irbesartan showed a significantly greater reduction in sitting cuff DBP at trough with olmesartan $(11.5 \mathrm{mmHg})$ than with losartan, valsartan, and irbesartan $(8.2,7.9$, and $9.9 \mathrm{mmHg}$, respectively, $\mathrm{p}<0.005$ olmesartan vs losartan; $\mathrm{p}<0.05$ olmesartan vs valsartan and irbesartan) (Oparil et al 2001). Reductions in cuff SBP with the four ARBs had the same numerical trend, but differences between treatments were not statistically significant due to variability in the data. The reduction in mean 24-hour DBP with olmesartan $(8.5 \mathrm{mmHg})$ was significantly greater than reductions with losartan and valsartan (6.2 and $5.6 \mathrm{mmHg}$, respectively, $\mathrm{p}<0.05$ ) and showed a trend toward significance compared with the reduction in DBP with irbe$\operatorname{sartan}(7.4 \mathrm{mmHg} ; \mathrm{p}=0.087)$. The reduction in mean 24-hour $\mathrm{SBP}$ with olmesartan $(12.5 \mathrm{mmHg})$ was significantly greater than those with losartan and valsartan $(9.0$ and $8.1 \mathrm{mmHg}$, respectively) and equivalent to the reduction with irbesartan (11.3 mmHg). All drugs were well tolerated.

The differences in BP reduction with olmesartan compared with other ARBs are attenuated at higher doses. In an 12-week, randomized, double-blind, forced titration study, 723 hypertensive patients were assigned to receive olmesartan, losartan, and valsartan (Giles et al 2007). Patients were randomized to olmesartan $20 \mathrm{mg}$, losartan $50 \mathrm{mg}$, valsartan $80 \mathrm{mg}$, or placebo, all once daily. Doses were titrated to 40 , 100, and $160 \mathrm{mg}$ once daily for olmesartan, losartan, and valsartan, respectively, after 4 weeks of treatment. At week 8, doses were titrated to $50 \mathrm{mg}$ twice daily for losartan and $320 \mathrm{mg}$ once daily for valsartan; olmesartan remained at the maximum recommended dose of $40 \mathrm{mg}$ once daily. All three medications significantly reduced mean seated DBP from baseline compared with placebo. At week 8, patients receiving olmesartan $40 \mathrm{mg}$ once daily had significantly greater reductions in mean seated DBP than those receiving losartan (-15.2/-12.9 vs -10.9/-9.4 mmHg, respectively, $\mathrm{p}<0.001)$; there was no significant difference compared with valsartan. A significantly greater percentage of patients achieved BP goals $(<140 / 90 \mathrm{mmHg}$ ) with olmesartan compared with losartan and valsartan $(39.7,19.8$, and $29.0 \%$, respectively, $\mathrm{p}<0.001$ vs losartan and $\mathrm{p}=0.031$ vs valsartan)

Olmesartan has vasoprotective and antiinflammatory effects that are unrelated to BP reduction. In the EUropean 
Trial on Olmesartan and Pravastatin in Inflammation and Atherosclerosis (EUTOPIA) study, investigators compared the antiinflammatory effects of olmesartan alone and with pravastatin in patients with essential hypertension and microinflammation (Fliser et al 2004). Olmesartan treatment significantly reduced serum levels of high-sensitivity C-reactive protein (CRP), high-sensitivity tumor necrosis factor-alpha (TNF- $\alpha$ ), interleukin-6 (IL-6), and monocyte chemotactic protein-1 (MCP-1) compared to placebo independently of BP reduction. Treatment with pravastatin alone did not significantly alter inflammation markers. The Vascular Improvement with Olmesartan medoxomil Study (VIOS) tested the hypothesis that suppression of RAAS with olmesartan reverses abnormal remodeling of resistance vessels and has favorable effects on central hemodynamics compared to suppression of sympathetic drive with the BB atenolol despite equivalent BP control (Smith et al 2007). In the presence of nearly physiological BP control, olmesartan reversed small resistance vessel remodeling virtually back to normal, while atenolol had little to no effect on the vascular wall. Further, olmesartan, but not atenolol, reduced the augmentation index. Thus, olmesartan has favorable effects on surrogate endpoints, but results of outcome trials are not yet available.

\section{Olmesartan - amlodipine combination \\ Pharmacology}

The pharmacokinetics of the olmesartan - amlodipine combination are equivalent to the pharmacokinetics of amlodipine and olmesartan medoxomil administered separately (Haworth et al 2007a; Rohatagi et al 2007; Salazar et al 2007). The bioavailability of the combination is well below $100 \%$, and is not affected by food (Haworth et al 2007b).

\section{Efficacy and safety}

The combination of olmesartan and amlodipine in a single tablet effectively reduces BP and attenuates the adverse events of the amlodipine component in hypertensive patients. An 8-week, multi-center, double-blind, randomized, placebocontrolled, parallel-group, factorial study of 1,940 subjects with mild to severe hypertension (seated DBP ranging from 99 to $120 \mathrm{mmHg}$ ) compared BP responses with placebo, monotherapy with amlodipine $5 \mathrm{mg}$ or $10 \mathrm{mg}$, with olmesartan medoxomil 10, 20, or $40 \mathrm{mg}$, and combination therapy with amlodipine - olmesartan medoxomil at doses of 5/10, $5 / 20,5 / 40,10 / 10,10 / 20$, and 10/40 mg (Chrysant et al 2007).
All combinations produced greater mean reductions in BP than either drug alone. The highest dose combination, amlodipine $10 \mathrm{mg}$ plus olmesartan $40 \mathrm{mg}$, reduced SBP by 30.1 $\mathrm{mmHg}$, a 53\% greater reduction than with $10 \mathrm{mg}$ amlodipine alone. DBP was reduced by $19 \mathrm{mmHg}$, compared with 12.7 $\mathrm{mmHg}$ for amlodipine alone. Addition of olmesartan to amlodipine decreased the amlodipine-related adverse effects. All combinations of amlodipine $10 \mathrm{mg}$ with olmesartan demonstrated less peripheral edema than amlodipine $10 \mathrm{mg}$ monotherapy.

\section{Patient perspective}

Although recent guidelines and advisory statements are recommending lower thresholds and goals for antihypertensive treatment, approximately two-thirds of patients do not achieve the goals. Population characteristics, such as increased life expectancy, higher obesity rates, and decreased physical activity, as well as provider characteristics, including inadequate attention to SBP elevations and the more aggressive BP goals recommended by recent guidelines, are factors that predispose to antihypertensive treatment resistance. For patients with difficult-to-control hypertension, the fixed-dose combination offers many advantages, such as convenience of use, fewer adverse events, greater antihypertensive potency, and lower cost.

\section{Conclusions}

Combination therapy is recommended by treatment guidelines and has become widely accepted by health care providers for the therapy of hypertension. Fixed-dose combinations provide effective antihypertensive treatment by achieving BP goals more frequently, improving patient adherence, and decreasing adverse effects.

Use of effective combination therapies blocks two or more BP regulatory systems, thus providing more effective and more physiologic reduction in BP than most monotherapies. Outcomes studies support inclusion of ARBs, such as olmesartan, and CCBs, such as amlodipine, in antihypertensive drug regimens.

\section{Disclosures}

Dr. Pimenta has no conflicts. Dr. Oparil has received grantsin-aid from Abbott Laboratories, AstraZeneca, Aventis, Biovail, Boehringer Ingelheim, Bristol Myers-Squibb, Forest Laboratories, GlaxoSmithKline, Novartis, Merck and Co, Pfizer, Sankyo Pharma, Sanofi-Synthelabo, and ScheringPlough; has served as consultant for Bristol Myers-Squibb, 
Daiichi Sankyo, Merck and Co, Novartis, Pfizer, Sanofi Aventis, and The Salt Institute; and is a member of Board of Directors for Encysive Pharmaceuticals.

\section{References}

Abernethy DR, Schwartz JB. 1999. Calcium-antagonist drugs. N Engl J Med, 341:1447-57.

ALLHAT Officers and Coordinators for the ALLHAT Collaborative Research Group. The Antihypertensive and Lipid-Lowering Treatment to Prevent Heart Attack Trial. 2002. Major outcomes in high-risk hypertensive patients randomized to angiotensin-converting enzyme inhibitor or calcium channel blocker vs diuretic: The Antihypertensive and Lipid-Lowering Treatment to Prevent Heart Attack Trial (ALLHAT). JAMA, 288:2981-97.

Bangalore S, Kamalakkannan G, Parkar S, et al. 2007. Fixed-dose combinations improve medication compliance: a meta-analysis. Am J Med, 120:713-9.

Basile J. 2004. The role of existing and newer calcium channel blockers in the treatment of hypertension. J Clin Hypertens, 6:621-9.

Beltman FW, Heesen WF, Smit AJ, et al. 1998. Effects of amlodipine and lisinopril on left ventricular mass and diastolic function in previously untreated patients with mild to moderate diastolic hypertension. Blood Press, 7:109-17.

Chobanian AV, Bakris GL, Black HR, et al. 2003. Seventh Report of the Joint National Committee on prevention, detection, evaluation, and treatment of high blood pressure. Hypertension, 42:1206-52.

Chrysant SG. 1994. Antihypertensive effectiveness of low-dose lisinoprilhydrochlorothiazide combination. Arch Intern Med, 154:737-43.

Chrysant SG, Melino M, Karki S, et al. 2007. A randomized, doubleblind, placebo-controlled factorial study evaluating the efficacy and safety of coadministration of amlodipine besylate (AML) plus olmesartan medoxomil (OM) compared to monotherapy in patients (PTS) with mild to severe hypertension (HTN) [abstract]. J Clin Hypertens, 9:486.

Chrysant SG, Weber MA, Wang AC, et al. 2004. Evaluation of antihypertensive therapy with combination of olmesartan medoxomil and hydrochlorothiazide. Am J Hypertens, 17:252-9.

Cushman WC, Ford CE, Cutler JA, et al. 2002. Success and predictors of blood pressure control in diverse North American settings: the Antihypertensive Lipid-Lowering treatment to prevent Heart Attack Trial (ALLHAT). J Clin Hypertens, 4:393-404.

Dahlöf B, Devereux RB, Kjeldsen SE, et al. 2002. CV morbidity and mortality in the Losartan Intervention For Endpoint reduction in hypertension study (LIFE): a randomized trial against atenolol. Lancet, 359:995-1003.

Dahlöf B, Sever PS, Poulter NR, et al. 2005. Prevention of CV events with antihypertensive regimen of amlodipine adding perindopril as required versus atenolol adding bendroflumethiazide as required, in the AngloScandinavian Cardiac Outcomes Trial-Blood Pressure Lowering Arm (ASCOT-BPLA): a multicenter randomized controlled trial. Lancet, 366:895-906.

Dezii CM. 2000. Medication noncompliance: what is the problem? Manag Care, 9:7-12.

Fliser D, Buchholz K, Haller H, et al. 2004. Antiinflammatory effects of angiotensin II subtype 1 receptor blockade in hypertensive patients with microinflammation. Circulation, 110:1103-7.

Gehi AK, Ali S, Na B, et al. 2007. Self-reported medication adherence and $\mathrm{CV}$ events in patients with stable coronary heart disease: the heart and soul study. Arch Inter Med, 167:1798-803.

Giles TD, Oparil S, Silfani TN, et al. 2007. Comparison of increasing doses of olmesartan medoxomil, losartan potassium, and valsartan in patients with essential hypertension. J Clin Hypertens, 9:187-95.

Hajjar I, Kotchen TA. 2003. Trends in prevalence, awareness, treatment, and control of hypertension in the United States 1988-2000. JAMA, 290:199-206.
Hasebe N, Kikuchi K, for the NICE Combi Study Group. 2005. Controlledrelease nifedipine and candesartan low-dose combination therapy in patients with essential hypertension: the NICE Combi (Nifedipine and Candesartan Combination) Study. J Hypertens, 23:445-53.

Haworth S, Bathala MS, Lee J, et al. 2007a. A fixed-dose combination of olmesartan medoxomil (OM) and amlodipine besylate (AM) is bioequivalent (BEQ) to free combination of the agents [abstract]. Clin J Hypertens, 9:A181.

Haworth S, Heyrman R, Bathala MS, et al. 2007b. The bioavailability (BAV) of a fixed-dose combination of olmesartan medoxomil (OM) and amlodipine besylate (AM) is unaffected by food [abstract]. Clin J Hypertens, 9:A181.

Kearney PM, Whelton M, Reynolds K, et al. 2005. Global burden of hypertension: analysis of worldwide data. Lancet, 365:217-23.

Jamerson K, Bakris GL, Dählof B, et al. 2007. Exceptional early blood pressure control rates: the ACCOMPLISH trial. Blood Press, 16:80-6.

Jamerson KA, Bakris GL, Wun CC, et al. 2004. Rationale and design of the avoiding $\mathrm{CV}$ events through COMbination therapy in Patients Living with Systolic Hypertension (ACCOMPLISH) trial: the first randomized controlled trial to compare the clinical outcome effects of first-line combination therapies in hypertension. Am J Hypertens, 17:793-801.

Julius S, Kjeldsen SE, Weber M, et al. 2004. Outcomes in hypertensive patients at high cardiovascular risk treated with regimens based on valsartan or amlodipine: the VALUE randomised trial. Lancet, 363:2022-31.

Julius S, Weber MA, Kjeldsen SE, et al. 2006. The Valsartan Antihypertensive Long-Term Use Evaluation (VALUE) trial: outcomes in patients receiving monotherapy. Hypertension, 48:385-91.

Khalil SA, Elzubier AG. 1997. Drug compliance among hypertensive patients in Tabuk, Saudi Arabia. J Hypertens, 15:561-5.

Krum H. 1997. Critical assessment of calcium antagonists. Aust Fam Physician, 26:841-5.

Laeis P, Puchler K, Kiech W. 2001. The pharmacokinetic and metabolic profile of olmesartan medoxomil limits the risk of clinically relevant drug interaction. J Hypertens, 19:S21-32.

Leenen FH, Wilson TW, Bolli P, et al. 1997. Patterns of compliance with once versus twice daily antihypertensive drug therapy in primary care: a randomized clinical trial using electronic monitoring. Can J Cardiol, 13:914-20.

Lewanczuk R, Tobe SW. 2007. More medications, fewer pills: combination medications for the treatment of hypertension. Can J Cardiol, 23:573-6.

Lewington S, Clarke R, Qizilbash N, et al. 2002. Age-specific relevance of usual blood pressure to vascular mortality: a meta-analysis of individual data for one million adults in 61 prospective studies. Lancet, 360:1903-13.

Lewis EJ, Hunsicker LG, Bain RP, et al. 1993. For the collaborative study group: the effect of angiotensin-converting-enzyme inhibitor on diabetic nephropaty. N Eng J Med, 329:1456-62.

Mancia G, De Backer G, Dominiczak A, et al. 2007. 2007 Guidelines for the management of arterial hypertension: the task force for the management of arterial hypertension of the European Society of Hypertension (ESH) and of the European Society of Cardiology (ESC). J Hypertens, 25:1105-87.

Messerli FH. 1993. Evolution of calcium antagonists: past, present, and future. Clin Cardiol, 26:II12-6.

Messerli FH, Oparil S, Feng Z. 2000. Comparison of efficacy and side effects of combination therapy of angiotensin-converting enzyme inhibitor (benazepril) with calcium antagonist (either nifedipine or amlodipine) versus high-dose calcium antagonist monotherapy for systemic hypertension. Am J Cardiol, 86:1182-7.

Michalsen A, Konig G, Thimme W. 1998. Preventable causative factors leading to hospital admission with descompensated heart failure. Heart, 80:437-41.

Miura S, Fujino M, Hanzawa H, et al. 2006. Molecular mechanism underlying inverse agonist of angiotensin II type 1 receptor. J Biol Chem, 281:19288-95. 
Miura S, Kiya Y, Kanazawa T, et al. 2008. Differential bonding interactions of inverse agonists of angiotensin II type 1 receptor in stabilizing the inactive state. Mol Endocrinol, 22:139-46.

Murphy J, Coster G. 1997. Issues in patient compliance. Drugs, 54:797-800.

Neaton JD, Grimm RH Jr, Prineas RJ, et al. 1993. Treatment of Mild Hypertension Study. Final results. Treatment of Mild Hypertension Research Group. JAMA, 270:713-24.

Neutel JM. 2001. Clinical studies of CS-866, the newest angiotensin II receptor antagonist. Am J Cardiol, 87:37C-43.

Neutel JM. 2005. Fixed combination antihypertensive therapy. In Oparil S, Weber MA (eds). Hypertension: a companion to Brenner and Rector's the kidney. 2nd ed. Philadelphia: Elsevier. p 522-9.

Neutel JM, Smith DH, Weber MA, et al. 2005. Efficacy of combination therapy for systolic blood pressure in patients with severe systolic hypertension: the Systolic Evaluation of Lotrel Efficacy and Comparative Therapies (SELECT) study. J Clin Hypertens, 7:641-6.

Ong KL, Cheung BMY, Man YB, et al. 2007. Prevalence, awareness, treatment, and control of hypertension among United States adults 1999-2004. Hypertension, 49:69-75.

Oparil S, Williams D, Chrysant S, et al. 2001. Comparative efficacy of olmesartan, losartan, valsartan and irbesartan in the control of essential hypertension. J Clin Hypertens, 3:283-91.

Oparil S, Silfani TN, Walker JF. 2005. Role of angiotensin receptor blockers as monotherapy in reaching blood pressure goals. Am J Hypertens, 18:287-94.

Packer M, O’Connor CM, Ghali KK, et al. 1996. Effect of amlodipine on morbidity and mortality in severe chronic heart failure. Prospective Randomized Amlodipine Survival Evaluation Study Group. N Engl J Med, 335:1107-14.

Paes AH, Bakker A, Soe-Agnie CJ. 1997. Impact of dosage frequency on patient compliance. Diabetes Care, 20:1512-7.

Philipp T, Smith TR, Glazer R, et al. 2007. Two multicenter, 8-week, randomized, double-blind, placebo-controlled, parallel-group studies evaluating the efficacy and tolerability of amlodipine and valsartan in combination and as monotherapy in adult patients with mild to moderate essential hypertension. Clin Ther, 29:563-80.

Pool JL, Glazer R, Weinberger M, et al. 2007. Comparison of valsartan/hydrochlorothiazide combination therapy at doses up to $320 / 25 \mathrm{mg}$ versus monotherapy: a double-blind, placebo-controlled study followed by long-term combination therapy in hypertensive adults. Clin Ther, 29:61-73.

Poulter NR, Wedel H, Dahlöf B, et al. 2005. Role of blood pressure and other variables in the differential CV events rates noted in the AngloScandinavian Cardiac Outcomes Trial-Blood Pressure Lowering Arm (ASCOT-BPLA). Lancet, 366:907-13.

Prisant LM. 2005. Calcium antagonists. In Oparil S, Weber MA (eds). Hypertension: a companion to Brenner and Rector's the kidney. 2nd ed. Philadelphia: Elsevier. p 683-704.

Prisant LM, Weir MR, Papademetriou V, et al. 1995. Low-dose drug combination therapy: an alternative first-line approach to hypertension treatment. Am Heart J, 130:359-66.

Rohatagi S, Haworth S, Heyrman R, et al. 2007. Low and high doses of a fixed-dose combination of olmesartan medoxomil (OM) and amlodipine besylate (AM) are bioequivalent (BEQ) to free combination of the agents [abstract]. Clin J Hypertens, 9:A178.
Rosamond W, Flegal K, Furie K, et al. 2008. Heart disease and stroke statistics - 2008 update: a report from the American Heart Association Statistics Committee and Stroke Statistics Subcommittee. Circulation, 117:e25-146.

Ruddy MC, Kostis JB. 2005. Angiotensin II receptor antagonists. In Oparil S, Weber MA (eds). Hypertension: a companion to Brenner and Rector's the kidney. 2nd ed. Philadelphia: Elsevier. p 683-704.

Salazar D, Lee J, Shenouda M, et al. 2007. Lack of pharmacokinetic (PK) drug interaction between olmesartan medoxomil (OM) and amlodipine besylate (AM) during coadministration [abstract]. Clin J Hypertens, 9:A180.

Schwocho L, Masonson H. 2001. Pharmacokinetics of CS-866, a new angiotensin II receptor blocker, in healthy subjects. J Clin Pharmacol, 41:515-27.

Sica D. 1994. Fixed dose combination antihypertensive drugs. Do they have a role in rational therapy? Drugs, 48:16-24.

Sica D. 2002. Rationale for fixed-dose combination in the treatment of hypertension: the cycle repeats. Drugs, 62:443-62.

Smith RD, Yokoyama H, Levy PJ, et al. 2007. Non-invasive hemodynamic data refflect treatment effects on vascular remodeling [abstract]. J Clin Hypertens, 9:A145.

Taddei S, Virdis A, Guiadoni L, et al. 2000. Antihypertensive drugs and reversing of endothelial dysfunction in hypertension. Curr Hypertens Rep, 2:64-70.

Taylor AA, Shoheiber O. 2003. Adherence to antihypertensive therapy with fixed-dose amlodipine besylate/benazepril HCL versus comparable component-based therapy. Congest Heart Fail, 9:324-32.

Terpstra WF, May JF, Smit AJ, et al. 2001. Long-term effects of amlodipine and lisinopril on left ventricular mass and diastolic function in elderly, previously untreated hypertensive patients: the ELVERA trial. J Hypertens, 19:303-9.

Turnbull F, Blood Pressure Lowering Treatment Trialists' Colaboration. 2003. Effects of different blood-pressure-lowering regimens on major CV events: results of prospectively-designed overviews of randomised trials. Lancet, 362:1527-35.

Veterans Administration Cooperative Study on Antihypertensive Agents. 1967. Effects of treatment on morbidity in hypertension. Results in patients with diastolic blood pressures averaging 115 through $129 \mathrm{~mm}$ Hg. JAMA, 202:1028-34.

Wanovich R, Kerrish P, Gerbino BP, et al. 2004. Compliance patterns of patients treated with 2 separate antihypertensive agents versus fixed-dose combination therapy [abstract]. Am J Hypertens, 17:223A.

Weir MR. 2008. Calcium antagonists. In Izzo JL Jr, Sica DA, Black HR (eds). Hypertension primer: the essentials of high blood pressure. Basic science, population science, and clinical management. 4th ed. Dallas: American Heart Association. p 465-9.

Weir MR, Dzau VJ. 2001. The rennin-angiotensin-aldosterone system: a specific target for hypertension management. Am J Hypertens, 12:177S-81.

Woodham RM, Oparil S. 2007. Fixed low-dose antihypertensive therapy. In Lang and Jones (eds). Comprehensive Hypertension. Philadelphia: Mosby Elsevier. p1061-73. 